\title{
Research of the Emotianal Inteligence of Bulgarian Physiotherapy Students
}

\author{
Nezabravka Gencheva $^{1^{*}} \quad$ Mariana Angelcheva ${ }^{2}$ Todor Marinov $^{3} \quad$ Ignat Ignatov $^{4}$ \\ 1.PhD, Professor, Department of "TM of Kinesitherapy", National Sports Academy Vasil Levski, 1 Gurgulyat \\ St., Sofia 1000, Bulgaria \\ 2.PhD, Medical Doctor, Senior Assistant Professor, Department of "Kinesitherapy and Rehabilitation", National \\ Sports Academy Vasil Levski, 1 Gurgulyat St., Sofia 1000, Bulgaria \\ 3.PhD, Assoc. Professor; Department "Theory and Methods of Physical Education" at National Sports Academy \\ "Vassil Levski", Sofia Bulgaria \\ 4.DSc, Professor, Scientific Research Center of Medical Biophysics (SRCMB), 32 N. Kopernik St., Sofia 1111, \\ Bulgaria
}

\begin{abstract}
Emotional intelligence is perceived as cognitive ability, social competence or personal disposition. It is a range of emotional competencies which determine the efficiency of human behavior.

The aim of the research was to establish the level of emotional intelligence of Bulgarian physiotherapy students and to compare it with the average values for the population. The subject of the research was a total of 50 students with major kinesitherapy who study at the National Sports Academy with mean age 23.5 years( $S=3,66): 23$ men and 27 women with mean age 22.96 years $(S=3,24)$ and 24 years $(S=3,96)$ respectively. We used Emotional Intelligence Questionnaire of Schutte, N. S., Malouff, J. M., Hall, L. E., Haggerty, D. J., Cooper, J. T., Golden, C. J. \& L. Dornheim. (1998). The SEIS consists of 33 items responded to on a 5-point Likert Scale.The possible range of scoresis from 33 to 165. This questionnaire was translated into Bulgarian in 2006 and adapted for Bulgarian conditions by StoyanovaS. (2010) with a sample consisting mainly of students $(\mathrm{N}=724)$. It allows to be interpreted as emotional intelligence both as a general construct and as different components of the construct. Results The physiotherapy students, included in this pilot research, show a little over average levels of emotional intelligence measured with the questionnaire of Schutte,etal (1998). With the advancement in age and experience the women show a little higher level of emotional intelligence. The Bulgarian version of the emotional intelligence scale of Schutte can be used for determining the level of emotional intelligence of students so that the level of their performance at university as well as their future professional realization can be prognosticated. Conclusion The higher emotional intelligence will help the future physiotherapeutic specialists to fulfill successfully their personal potential. They will have a positive social attitude and good ability for adaptation in the community environment. They will also be able to build healthy relationships with their patients which is a major factor for their motivation to actively take part in the healing process.
\end{abstract}

DOI: $10.7176 / \mathrm{JMPB} / 52-03$

\section{Introduction}

Emotions are conditions characterized with suddenly arising excitement leading to changes in human's thoughts and behavior. Emotions reflect the subjective human attitude towards the events in life which could be hardly controlled. In order to gain control over emotions people have to possess a certain level of self-knowledge and should examine their own personal traits affecting their behavior and reactions. People differ according to their level of consciousness and understanding of the way the different situations, events, people and other stimuli generate emotions.

The different ways of showing human emotions are assessed through Emotional intelligence which is a relatively new area of study. Despite Darwin postulated that emotional expression was of primary importance for survival, emotional intelligence (EI) was mentioned for the first time in 1920s. The roots of EI, however, could be found in Thorndike's research in 1920 (Pérez etal). Thorndike viewed the ability to understand and manage people and to act reasonably within human relationships. Gardner (1983)developed the concept for intrapersonal intelligence which is the ability to understand oneself and assess one's own feelings and motivation and interpersonal intelligence which is related to the ability to comprehend the others' expectations, motivation and desires. These two integrative parts, according to Gardner,formed the emotional intelligence.

According to GoldmenD (2000) emotional intelligence consists of the following qualities: self-control over one's mood and impulses, perseverance and motivation, integrity, empathy, optimism, frustration stability, and postponing satisfaction seeking.

PeterSalovey andMayer, Salovey (1990) introduced the model of emotional intelligence which reflects the self-evaluation of emotions and the emotions of others and their regulation, emotional expression, self-control over impulses and the use of one's own emotions in problem solving. These researchers held the first empirical studies in the context of Chinese medical philosophy that values unity, harmony and balance, part of which is the 
emotional intelligence (Marinova, 2015). The initial concept of emotional intelligence is related to the cognitive ability for processing the information connected with emotions. Later, Mayer, Salovey, andCaruso (2004) improved their model by adding other characteristics related to the role of personal traits, individual differences and connection with the intellect such as the ability to express feelings, ability to counteract failures, motivation maintenance, empathy, intimacy and optimism, well-meant and ethical behaviour (Kardasheva, Stoyanova, 2008, 2009, Goleman,1995; DulewiczandHiggs (1999)Albreht, K. , 2006). According to the other concept of EI of Petrides\&Furnham (2001)this construct is not related to the cognitive human abilities, as it is traditionally defined, but is rather based on personal and behaviour dispositions. EI measures the individuals' perceptions of their typical emotional abilities such as regulation, identification / assessment and use of emotions in a particular situation. According to the model of Petrides\&Furnham(2001)individuals could defer by the way they perceive and process the emotional information coming from their intrapersonal core and from interpersonal relationships.

The high values of emotional intelligence help not only the self-control in emotional responses (especially in crisis situations) but also the reduction of emotional burnout. That is why EI has been widely examined in the last decade in business organisations because it is an important aspect of good leaders' efficiency in work environment (George,2000; Kobe, Reiter-Palmon, \&Rickers, 2001, Caruso, Mayer, \&Salovey, 2002;

Rosete\&Ciarrochi, 2005). Adeyemo, D.A. (2007) in a research done among 300 students found out that emotional intelligence and academic efficiency correlate significantly with the academic achievements.

A number of authors distinguish emotional intelligence as a trait of a person's intelligence. Various scientific studies have found lack of correlation between the questionnaires for emotional intelligence and the IQ tests.

As mentioned above emotional intelligence is perceived as cognitive ability as well as social competence or personal disposition. It is a crucial determining factor for individual differences in behaviour in different social spheres and particularly in interpersonal communication (Kardasheva, A). That is why it finds a wide practical application in a number of professional fields such as medicine, education, psychology, business, economics, sport, politics, etc. For example, a study was held among 30 handball players aimed at determining how emotional intelligence, being a trait, influenced coping with stress coming from their competitors. Athletes with high level of EI showed better coping strategies compared to those ones with lower levels of EI as personal trait (Labordeetal.2011).

Emotional intelligence not only leads to comprehension of one's own emotions bur also to use of these emotions in a functional way. Emotions could be beneficial as regards directing attention to first-hand problems. They could be used when choosing among options and taking decisions; when we can anticipate how we will feel under certain circumstances. The changes in emotions could lead to more flexible planning, to reaching a number of alternatives regarding problem solving.

In the recent years a particular attention has been paid to studies of emotional intelligence as a necessary criterion for admission of students in the medical field (Liebermanetal.,1998). In physiotherapeutic practice, being part of medical care, certain personal qualities are needed besides professional knowledge and skills. Developing emotional intelligence is very important in working environment. It can guarantee tolerance, successful communication with patients and colleagues, higher level of empathy and understanding patients' emotions related to their illness, more efficient team work, solving conflicts, tolerance of criticism and using it constructively. The emotions influence the processes of perception and communication. Although childhood is the critical period for its formation, it is by no means determined by birth and can be nourished and developed throughout life with immediate benefits for human's health and work.

Being lecturers of kinesitherapy students, we should know the level of their emotional intelligence in order to improve the pedagogical process, on the one hand, and to improve the efficiency of the communication between lecturers, students and patients, on the other hand.

Aim of the research To determine the level of emotional intelligence of Bulgarian students with major physiotherapy

We formulated the following hypothesis: The degree of emotional intelligence of the researched group is higher compared to the average one for the Bulgarian population.

\section{Method andParticipants}

The research was done among a total of 50 students with major kinesitherapy who study at the National Sports Academy with mean age $23.5(\mathrm{~S}=3.66)$ : 23 men and 27 women with mean age 22.96 years $(\mathrm{S}=3,24)$ and 24 years $(\mathrm{S}=3,96)$ respectively.

We conditionally divided the participants into two groups: the first group consisted of BA students in the last year of their studies, MA students and Ph.D. students (Gr1); the second group consisted of BA students in the first year of their studies $(\mathrm{Gr} 2)$. The mean age of $\mathrm{Gr} 1$ is $25.05(\mathrm{~S}=2.96)$ and ofGr2 - $19.08(\mathrm{~S}=0.49)$. The mean age of the men in group M1 is $24.75(\mathrm{~S}=2.18)$, and of women - F1 is 24.29 ( $\mathrm{S}=3.480558)$. The mean age of the men in group M2 is $18,86(\mathrm{~S}=0.38)$, and of women - $\mathrm{F} 2$ is $19.33(\mathrm{~S}=0.52)$. 


\section{Methods}

Ethical considerations After having been explained the aim and significance of the research, the students provided their oral consent for the experiment. All participants were assured that their answers were anonymous and the information - confidential. The instrument was administered to the students at the beginning of the winter semester of academic year 2017/2018.

Everybody completed the emotional intelligence questionnaire of Schutte, N. S., Malouff, J. M., Hall, L. E., Haggerty, D. J., Cooper, J. T., Golden, C. J. \& L. Dornheim. (1998 The SEIS consists of 33 items responded to on a 5-point Likert scale. The possible range of scores is from 33 to 165). This questionnaire was translated into Bulgarian in 2006 and adapted for Bulgarian conditions by StoyanovaS. (2010)with a sample consisting mainly of students $(\mathrm{N}=724)$. It allows to interpret emotional intelligence both as a general construct and as different components of the construct. Average norms were determined as well as norms for low and high intelligence.

In its latest version the questionnaire consists of 33 items responded to on 5-point Likert scale. There are four factors: Sharing of emotions and empathy $(\alpha=0.7551)$; Motivation for the overcoming of difficulties and optimism $(\alpha=0.7509)$; Recognizing of other people's non-verbal expression of emotions $(\alpha=0.7444)$; and Recognitionof own emotions and self-control $(\alpha=0.6055)$. The reliability of the whole test is $\alpha=0.7263$.In the Bulgarian version items 5,28 and 33 are reverse-scored.

One drawback of SEIS is the fact that it doesn't fully cover all aspects of EI Schutte et al. (1998). Nevertheless, we chose it for our research due to its popularity in literature as well as because of the fact it is a short and easy option for a global assessment of EI as a personal trait.

\section{Results}

The Statistical Package for Social Sciences (SPSS) version20 was used for data analysis. Descriptive statistics was used as well as One sample T-test to examine the differences between the students. A statistically significant difference was considered at $p$-value $p \leq 0.05$ and a high statistically significant difference was considered at $p$ value $\mathrm{p} \leq 0.001$.

The results from the researched factors with both groups of subjects are presented in Table 1.

Table 1. Comparison of the emotional intelligence between the two age groups of subjects

\begin{tabular}{|c|c|c|c|c|c|c|c|c|}
\hline \multirow[b]{2}{*}{ Factors } & \multicolumn{3}{|c|}{ Gr 1} & \multicolumn{3}{|c|}{ Gr 2} & \multirow[b]{2}{*}{ d } & \multirow{2}{*}{$\mathbf{P \%}$} \\
\hline & $\mathbf{n}$ & $\overline{X_{1}}$ & S1 & n & $\bar{X}_{2}$ & S2 & & \\
\hline Sharing of emotions and empathy & 37 & 25,46 & 3,42 & 13 & 24,77 & 5,43 & 0,69 & 36 \\
\hline Motivation for the overcomingofdifficultiesandoptimism & 37 & 33,78 & 5,11 & 13 & 32,85 & 8,51 & 0,93 & 60 \\
\hline $\begin{array}{l}\text { Recognizing of other people's non-verbal expression of } \\
\text { emotions }\end{array}$ & 37 & 19,22 & 3,48 & 13 & 18,38 & 3,88 & 0,84 & 52 \\
\hline Recognition of own emotions and self control & 37 & 17,62 & 2,51 & 13 & 15,54 & 4,63 & 2,08 & 95 \\
\hline Total score of emotional intelligence & 37 & 132,27 & 12,19 & 13 & 123,39 & 26,19 & 8,88 & 89 \\
\hline
\end{tabular}

Total score of emotional intelligence

Recognition of own emotions and selfcontrol

Recognizing of other people's non-verbal expression of emotions

Motivation for the overcoming of difficulties and optimism

Sharing of emotions and empathy

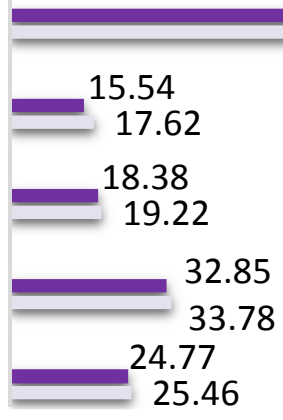

50
0
Gr2 =13

100
Gr1 $=37$

150

Fig.1 Graphic expression of the emotional intelligence of the age groups

The data in table 1 and figure 1 show that along the factor Sharing of emotions and empathythere is no significant difference between the two groups Gr1 first-year BA students and Gr2 last-year BA students, MA students and Ph.D. students. There are similar results whencomparing both groups along the factor Motivation for the overcoming of difficulties and optimism. The respondents from the two age groups show similar values without statistical significance of the differences. This is probably due to young people's continuous aspiration to personal and professional development. Along the third factor from the questionnaire 
Recognizing of other people's non-verbal expression of emotionswe determined that the values between the two groups were close. They possess a good level of understanding of the human emotions and interpersonal interactions with their patients, of creating a feeling of mutual trust. Perhaps this personal disposition affected their choice of profession.

Along the factor Recognition of own emotions and selfcontrolwe notice quite higher values which are statistically significant $(\mathrm{p}<0,05)$ in favor of Gr1. Most of the participants in this group are active athletes which is probably the reason for their good self-control in relation to their skills for abiding by the rules in sport and gained life experience for control over their feelings and emotions.

There is a trend for higher values along the factor Total score of emotional intelligence with Gr1, despite the lack of statistically significant difference $(\mathrm{p}>0.05)$.

Table 2 Comparison of the emotional intelligence of the two female groups of subjects

\begin{tabular}{|l|c|c|c|c|c|c|c|c|}
\hline \multirow{2}{*}{ Factors } & \multicolumn{3}{|c|}{ Froups } & \multicolumn{3}{|c|}{ F2 } & \multirow{2}{*}{ d } & \multirow{2}{*}{ P\% } \\
\cline { 2 - 8 } & $\mathbf{n}$ & $\overline{\boldsymbol{X}}_{1}$ & $\mathrm{~S} 1$ & $\mathbf{n}$ & $\overline{\bar{X}}_{2}$ & $\mathrm{~S} 2$ & & \\
\hline Sharing of emotions and empathy & 21 & 26,24 & 2,79 & 6 & 23,00 & 7,18 & 3,24 & 97 \\
\hline Motivation for the overcoming of difficulties and optimism & 21 & 35,52 & 3,52 & 6 & 31,17 & 11,94 & 4,35 & 99 \\
\hline $\begin{array}{l}\text { Recognizing of other people's non-verbal expression of } \\
\text { emotions }\end{array}$ & 21 & 20,38 & 2,89 & 6 & 18,17 & 4,54 & 2,21 & 85 \\
\hline Recognition of own emotions and self control & 21 & 17,90 & 2,32 & 6 & 15,50 & 5,39 & 2,40 & 94 \\
\hline Total score of emotional intelligence & 21 & 137,04 & 9,67 & 6 & 118,67 & 36,21 & 18,37 & 99 \\
\hline
\end{tabular}

Total score of emotional intelligence

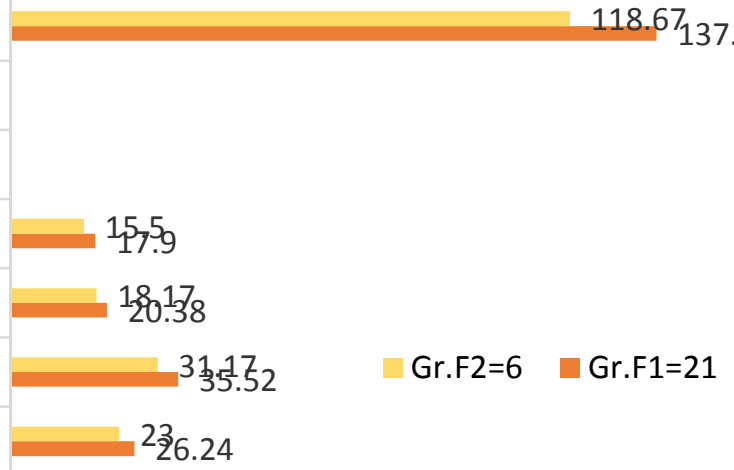

Recognition of own emotions and selfcontrol Recognizing of other people's non-verbal expression of emotions

Motivation for the overcoming of difficulties and optimism

Sharing of emotions and empathy

$\begin{array}{llllllll}0 & 20 & 40 & 60 & 80 & 100 & 120 & 140\end{array}$

Fig. 2 Graphic expression of the emotional intelligence of the two female groups of subjects

When comparing the level of emotional intelligence of the two female age groups presented in table 2 and figure 2 we determine statistically significant higher values along the factors Sharing of emotions and empathy $(\mathrm{p}<0,05)$, Motivation for the overcoming of difficulties and optimism $(\mathrm{p}<0,005)$, as well as the final global score of emotional intelligence $(p<0,005)$. Emotions are more strongly expressed by women.

The results between the two male age groups are interesting. They are presented in table 3 and figure 3 but they do not show statistically significant differences in the factors. Yet, there is a trend for higher values along three of the factors with the younger age group. There is no statistically significant difference in the global score of emotional intelligence either. In the present study there are no significant age differences in emotional intelligence of men which is revealed exactly as personal EI trait in this case, i.e. as a relatively changeable variable assessing globally trait EI.

Table 3. Comparison of the emotional intelligence of the two male groups of subjects

\begin{tabular}{|l|c|c|c|c|c|c|c|c|}
\hline \multirow{2}{*}{ Factors Groups } & \multicolumn{3}{|c|}{$\mathbf{M} \mathbf{2}$} & \multicolumn{3}{c|}{ M 1 } & \multirow{2}{*}{ P\% } \\
\cline { 2 - 9 } & $\mathbf{n}$ & $\overline{\bar{X}} 1$ & S1 & $\mathbf{n}$ & $\overline{\bar{X}} 2$ & S2 & d & P \\
\hline Sharing of emotions and empathy & 7 & 24,44 & 3,97 & 16 & 26,29 & 3,20 & 1,85 & 57 \\
\hline $\begin{array}{l}\text { Motivation for the overcoming of difficulties and } \\
\text { optimism }\end{array}$ & 7 & 31,50 & 6,03 & 16 & 34,29 & 4,57 & 1,09 & 29 \\
\hline $\begin{array}{l}\text { Recognizing of other people's non-verbal } \\
\text { expression of emotions }\end{array}$ & 7 & 17,69 & 3,68 & 16 & 18,57 & 3,60 & 1,88 & 49 \\
\hline Recognition of own emotions and self control & 7 & 17,25 & 2,77 & 16 & 15,57 & 4,32 & 1,68 & 93 \\
\hline Total score of emotional intelligence & 7 & 126,00 & 12,56 & 16 & 127,43 & 15,44 & 1,43 & 49 \\
\hline
\end{tabular}


Total score of emotional intelligence

Recognition of own emotions and selfcontrol

Recognizing of other people's non-verbal expression of emotions

Motivation for the overcoming of difficulties and optimism

Sharing of emotions and empathy

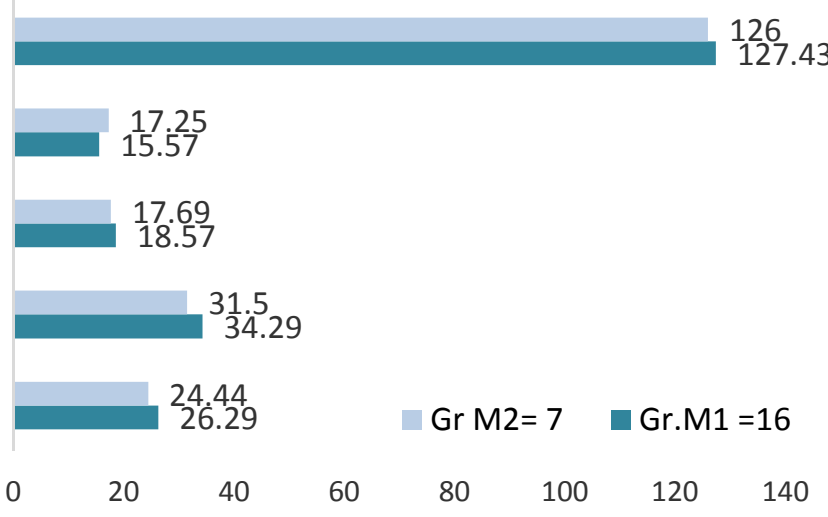

Fig. 3 Graphic expression of the emotional intelligence of the two male groups of subjects

In literature a number of researchers such as King (1999), Sutarso (1999), Wing and Love (2001) and Singh (2002) (по Ahmad et al.,2009) found a higher emotional intelligence in favor of women. It was a challenge for us to find out whether there are gender differences between the male and female students with major physiotherapy along the factors determining the emotional intelligence and its total score (table 4 and figure 4).

Table 4. Comparison of the emotional intelligence of male and female kinesitherapy students

\begin{tabular}{|l|c|c|c|c|c|c|c|c|}
\hline \multirow{2}{*}{ Factors Groups } & \multicolumn{3}{|c|}{ M } & \multicolumn{3}{c|}{ F } & \multirow{2}{*}{ P\% } \\
\cline { 2 - 8 } & $\mathbf{n}$ & $\overline{\bar{X}} 1$ & S1 & $\mathbf{n}$ & $\overline{\bar{X}} 2$ & S2 & P \\
\hline Sharing of emotions and empathy & 23 & 25,00 & 3,78 & 27 & 25,52 & 4,22 &, 52 & 35 \\
\hline $\begin{array}{l}\text { Motivation for the overcoming of difficulties and } \\
\text { optimism }\end{array}$ & 23 & 32,35 & 5,68 & 27 & 34,55 & 6,35 & 2,20 & 79,5 \\
\hline $\begin{array}{l}\text { Recognizing of other people's non-verbal } \\
\text { expression of emotions }\end{array}$ & 23 & 17,96 & 3,60 & 27 & 19,89 & 3,36 & 1,93 & 95 \\
\hline Recognition of own emotions and self control & 23 & 16,74 & 3,31 & 27 & 17,37 & 3,28 &, 63 & 50 \\
\hline Total score of emotional intelligence & 23 & 126,44 & 13,16 & 27 & 132,96 & 19,62 & 6,52 & 82 \\
\hline
\end{tabular}

Total score of emotional intelligence

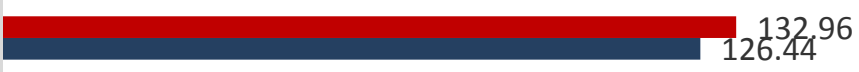

Recognition of own emotions and selfcontrol

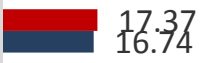

Recognizing of other people's non-verbal..

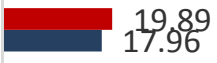

Motivation for the overcoming of difficulties and...

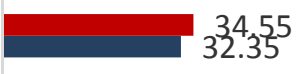

Sharing of emotions and empathy

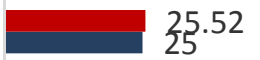

GrF=27 Gr M= 23

0

50

100

Fig. 4 Graphic expression of the emotional intelligence of male and female kinesitherapy students

Figure 4 reveals graphically insignificant differences between male and female physiotherapy students both in the total score of emotional intelligence and in the different factors, except for Recognizing of other people's non-verbal expression of emotions $(\mathrm{p}<0,05)$. These data show that the women in our research probably possess better social skills in recognizing the feelings of others even when these feelings are subtle.

We compared the results from the questionnaire of the whole group of physiotherapists with the average statistical norms for the Bulgarian population in the test adaptation of Stoydnova. We established statistically significant higher values of the physiotherapists along the factor Recognizing of other people's non-verbal expression of emotions $(p<0,05)$ and Recognition of own emotions and self-control $(p<0,05)$, as well as in Total Score of Emotional Intelligence $(\mathrm{p}<0,05)$. 
Table 5 Comparison of the emotional intelligence of students with major physiotherapy and the mean values for the population with the questionnaire adapted by Stoyanova (2010).

\begin{tabular}{|l|c|c|c|c|c|c|c|c|}
\hline \multirow{2}{*}{ Groups } & \multicolumn{3}{|c|}{$\begin{array}{c}\text { All students in the } \\
\text { research }\end{array}$} & \multicolumn{3}{c|}{ Mean values } & \multirow{2}{*}{ d } & \multirow{2}{*}{ P\% } \\
\cline { 2 - 8 } & $\mathbf{n}$ & $\overline{X_{1}}$ & $\mathrm{~S} 1$ & $\mathbf{n}$ & $\overline{X_{2}}$ & $\mathrm{~S} 2$ & & \\
\hline Sharing of emotions and empathy & 50 & 25,3 & 3,99 & 724 & 24,7 & 4,2 & 0,6 & 58 \\
\hline $\begin{array}{l}\text { Motivation for the overcoming of difficulties } \\
\text { and optimism }\end{array}$ & 50 & 33,5 & 6,09 & 724 & 32,9 & 5,6 & 0,6 & 56 \\
\hline $\begin{array}{l}\text { Recognizing of other people's non-verbal } \\
\text { expression of emotions }\end{array}$ & 50 & 19,0 & 3,57 & 724 & 17,9 & 3,5 & 1,1 & 95 \\
\hline Recognition of own emotions and self control & 50 & 17,1 & 3,28 & 724 & 14,9 & 3,3 & 2,2 & 99 \\
\hline Total score of emotional intelligence & 50 & 130,0 & 17,11 & 724 & 124,5 & 15,6 & 5,5 & 96 \\
\hline
\end{tabular}

Total score of emotional intelligence

Recognition of own emotions and selfcontrol

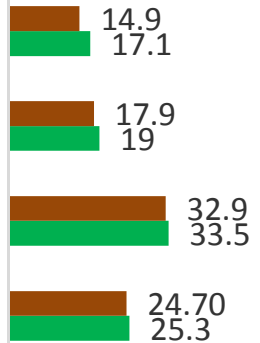

$\mathrm{Gr} \mathrm{N}=724$

Gr All 50

0

50

100

Fig. 5 Comparison of the emotional intelligence of students with major physiotherapy and the mean values for the population

\section{Discussion}

Why do we actually need to know the level of emotional intelligence? According to Dulewicz \& Higgs (2001) by the level of emotional intelligence we can predict one's quality of work. Emotional intelligence is a powerful factor of social interactions under different circumstances - in family and business environment. Emotions are of great importance for ensuring good health care. High levels of emotional intelligence suppose skills and abilities such as social regulation, self-control, stress management, social consciousness and motivation. The affectivereceptivity and the ability to comprehend both one's own and the other's position, motives and emotions is more important for some working environments then it is for others. Such is the working environment of the physiotherapists. The development of empathy and assertiveness skills is crucial for their work. Research of the empathic behavior of the specialists in the field of physiotherapy is necessary for the better understanding of patients' problems. They can consider things from their point of view and can provide them with quality physiotherapeutic care. The greater manifestation of empathy in the field of physiotherapy could help relationship management. The specialists would avoid stereotypes and would develop their clinical thinking. The assertive behavior reflects the understanding of the personal value of each individual which is important for creating trust between patients and therapists.

On the base of the results from the present study and the answers to research questions we can conclude that physiotherapy students, involved in this pilot study, show a little over average levels of emotional intelligence, measured with the help of the questionnaire of Schutte, etal (1998); and with the advancement in age and experience women show higher levels. The obtained values along the different factors and the total global score of the questionnaire show that physiotherapy students, involved in the research, are able to control their own mood, handle their emotions, gain control over their impulses, are frustration stable, and do not allow for the failures to suppress their ability for rational thinking. The efficient understanding of themselves and their own behavior, as well as the emotions and behavior of others can help them in the development of their intuition in difficult situations related to taking important decisions and in the choice of clinical approaches to patients. To help people with mental and physical disabilities is a manifestation of social ability to adapt and optimistic attitudes, which is related exactly to high levels of emotional intelligence.

The physiotherapy students, taking part in the present research, show a great desire for personal success. They 
are motivated to face challenges and overcome difficulties in both personal and professional sphere and we can assume that the future specialists-participants in this pilot study will probably maintain a normal working environment and will have good communication with their patients and the other members of the rehabilitation team. We can determine the level of physiotherapists' emotional intelligence as one of the components of their competence. The higher emotional intelligence could, after all, predetermine better and more efficient care for the patients.

Our research showed there are significant differences in the women's level of EI according to their age along two of the factors and in the global score. Similar results were obtained by Fernández-Berrocal etal2012 with "Mayer, Salovey, Caruso Emotional Intelligence Test" (MSCEIT; Mayer, Salovey, \& Caruso, 2002). They determined a change in the dimensionof emotions management with the advancement in age and gender difference in the emotional intelligence. Other researchers of EI have found out that women have greater emotional knowledge, are able to express their positive and negative emotions more often and possess a greater number of interpersonal competences and social experience (Brody\&Hall, 2000; Ciarrochi, Hynes\&Crittenden, 2005; VanRooyetal, 2006). Such conclusions were drawn in surveys done by Tapia (1999) and Dunn (2002) (Ahmad et al.,2009). They noticed that girls showed greater empathy and social responsibilities in their interpersonal relationships than boys. Girls are more sensitive to their relations with relatives and close friends. All these traits could explain their greater emotional intelligence compared to boys. According to Stoyanova (2011) female students in Bulgaria show higher emotional intelligence due to the more greatly expressed ability to share emotions and empathy, as well as their stronger motivation for overcoming difficulties and their optimism. The values of emotional intelligence in the research show there is a trend for a little higher value with female physiotherapists which are, however, statistically insignificant compared to those with men with the exception of thefactor Recognizing of other people's non-verbal expression of emotions. We consider that both male and female physiotherapists are emotionally intelligent in different ways. While women are more empathic and socially communicative, men, on the other hand, are more self-confident, optimistic and adaptive to various difficult situations.

Our pilot study determined higher levels of emotional intelligence in one professional group in the field of health care such as physiotherapists, which confirms the hypothesis we formulated. The adapted for Bulgarian conditions emotional intelligence scale of Schutte can be applied to determine the level of emotional intelligence of the students and to help prognosticating the level of their performance both in university and working environment.

\section{Conclusion}

We can define emotional intelligence as a number of emotional competencies which determine the efficiency of human behaviour. Although a lot of authors define emotional intelligence as a trait, it could be developed throughout life while people observe, listen and build their self-consciousness and sense of responsibility. This process is one of the most significant ones in the development of a person. The way one manages one's own feelings and behaviour and the ability to cope with one's mood and other people's emotions is an important criterion for success.

If physiotherapy students possess high emotional intelligence, they will fulfil successfully their personal potential, will have a positive social attitude and good ability to adapt, will be able to build healthy relations with their patients which is an important factor for the stimulation of their motivation to actively taking part in the healing process and increasing the level of its efficiency. In this relation we are interested in doing a future research in the connection between emotional intelligence and the pass-rate of the students.

\section{Bibliography}

Adeyemo,.A. (2007) Moderating Influence of Emotional Intelligence on the Link between Academic self Efficacy and Achievemen to University Students, Psychologyand Developing Societies, 19, 199-213.

Ahmad, S., Bangash, H.Ahmad\&Kan, S. (2009). Emotional Intelligence and Gender Differences, Sarhad J. Agric., 25 (1): 127-130.

Al-Nasser, A, Al-Enezy M.,(2018) The Big Five Factors of Personality and Its Relation to Emotional Intelligence among Leaders of Educational Institutionsinthe State of Kuwait, Psychology, 9, 1680-1694

Austin, E.J., Saklofske, D.H., Huang, S.H.S., \&McKenney, D. (2004). Measurement of traitemotional intelligence,Testingandcross-validating a Modified Versionof Schutteetal.'s Measure, Personality and Individual Differences, 36, 555-562.

Brody, L., Hall, J. (2000). Gender, Emotion, Andexpression, In M. Lewis, \& J. M. Haviland (Eds.), Hand Book of Emotions, New York: Guilford, 338-349

Ciarrochi, J.., Hynes, K., Crittenden, N. (2005). Can Men Do Better if They Try Harder? Sex and Motivational Effects one Emotional Awareness, Cognition and Emotion, 19, 133-141

Caruso, D.R., Mayer, J.D., \&Salovey, P. (2002). Emotional Intelligence and Emotional leadership. In R.E.Riggio, 
S.E. Murphy, \& F.J. Pirozzolo (Eds.), Multiple Intelligences and Leadership, Mahwah, NJ: LawrenceErlbaum Associates, 55-74.

Dulewicz, V. \&Higgs, M. (2001). Emotional Intelligence Questionnaire (DHEIQ)

Fernández-Berrocal, Cabello R., Castillo\&Extremera N. (2012) Gender Differences in Emotional Intelligence, The mediating Effect of Age, Behavioral Psychology / Psicología Conductual, 20 (1), 77-89

Hwang, S., Feltz, D., Lee, J., (2013). Emotional Intelligence in Coaching: Mediation Effect of Coaching Efficacy on the Relationship between Emotional intelligence and leadership Style, International Journal of Sport and Exercise Psychology, 11 (3), 292-306

Goldmen D. (2000) Emotional Intelligence S, Kibea (in Bulgarian).

Heba, A-F I et al..(2016) Relationship Between Nursing Students' , Emotional Intelligence and Their Clinical Performance During Obstetrics and Gynaecologic Nursing PracticalTraining, American Journal of Nursing Science, 5 (6): 240-250

Kardasheva, A. (2015) Emotional Intelligence as a Type of Communication, Rhetoric and Communicationsq eJournal ;http://rhetoric.bg/

Kobe, L.M., Reiter-Palmon, R., \&Rickers, J.D. (2001).Self-reported Leaders experiences in relation to inventoried social and emotional intelligence, Current Psychology, 20, 154-163.

Laborde S., Brüll A., Weber J. \&Anders L., (2011) Trait Emotional Intelligence in Sports, A Protective Role against Stress Through Heart Rate Variability, Personality and Individual Differences, 51 (1): 23-27.

Lieberman S, Stroup-Benham C, \& Peel J. (1998). Predictors of Intellectual Satisfaction in Medical School: Sociol, Demographic, Cognitive and Personality factors, Acad Med, 73 (10):44-46

Marinova, D. \& Wu Xing., (2015) The Art of Balance According to Traditional Chinese Medicine, Collection of Papers from the Second International Conference on Chinese Studies ,, The silk of road, 91-95.

Schutte, N. S., Malouff, J. M., Hall, L. E.,Haggerty, D. J., Cooper, J. T., Golden, C. J. \&L.Dornheim. (1998). Development and Validation of a Measure of Emotional Intelligence, Personality and Individual Differences, 25 (1998), 167-177

Petrides, K.V., \&Furnham, A. (2003). Trait Emotional Intelligence: Behavioral Validation in Two Studies of Emotion Recognition and Reactivity to Mood Induction. European Journal of Personality, 17, 39-57.

Petrides, K. V. (2011). Ability and Trait Emotional Intelligence, In T. Chamorro-Premuzic, S. Von Stumm \& A. Furnham (Eds.), The Wiley-Black Well Handbook of Individual differences, New York, NY: Wiley, 656-678.

Rosete, E.\&Ciarrochi, F. (2005) Emotional Intelligence and its Relationship to Work Place Performance out Comes of Leader Ship Effectiveness, Leadership\&Organization Development Journal, 26, 388-399.

Salovey, P., \&Mayer, J.D. (1990). Emotional Intelligence, Imagination, Cognitionand Personality, 9, $185-211$.

Stoyanova, S. (2010). EmotionalIntelligence-MeasurementandRelatedConstructs. Adaptationof a questionnaire. Saarbrucken: LambertAcademicPublishing

Stoyanova, S. (2011). Emotional Intelligence and Personality Constructs, Romanian Journal of School Psychology, 4 (8), 57-75.

Tapia, M.L. (1999) A Study of the Relationships of the Emotional Intelligence in Ventory (Intelligencetests). Dissert. Abst. Int

VanRooy, D. L., Dilchert, S., Viswesvaran, C., \&Ones, D. S. (2006). Multiplying Intelligences: Are General, Emotional, and Practical Intelligence Sequal? In K. R. Murphy (Ed.), A Critique of Emotional Intelligence; Mahwah, NJ: Erlbaum; 235-262 